\title{
Income inequality and the double burden of under- and overnutrition in India
}

\author{
S V Subramanian, Ichiro Kawachi, George Davey Smith
}

J Epidemiol Community Health 2007;61:802-809. doi: 10.1136/jech.2006.053801

See end of article for authors' affiliations

Correspondence to: S V Subramanian, Department of Society, Human Development and Health, Harvard School of Public Health, 677

Huntington Avenue, KRESGE 7th Floor, Boston, MA

02115-6096, USA: svsubram@hsph.harvard. edu

Accepted 13November 2006

\begin{abstract}
Objectives: Developing countries are increasingly characterised by the simultaneous occurrence of underand overnutrition. This study examined the association between contextual income inequality and the double burden of under- and overnutrition in India.

Design: A population-based multilevel study of 77220 ever married women, aged 15-49 years, from 26 Indian states, derived from the 1998-99 Indian National Family Health Survey data. The World Health Organization recommended categories of body mass index constituted the outcome, and the exposure was contextual measure of state income inequality based on the Gini coefficient of per capita consumption expenditure. Covariates included a range of individual demographic, socioeconomic, behavioural and morbidity measures and state-level economic development.

Results: In adjusted models, for each standard deviation increase in income inequality, the odds ratio for being underweight increased by $19 \%(p=0.02)$ and the odds ratio for being obese increased by $21 \%$ $(p<0.0001)$. Income inequality had a similar effect on the risk of being overweight as it did on the risk of obesity $(p=0.01)$, and state income inequality increased the risk of being pre-overweight by $9 \%(p=0.01)$. While average levels of state economic development were strongly associated with degrees of overnutrition, no association was found with the risk of being underweight.

Conclusions: Rapidly developing economies, besides experiencing paradoxical health patterns, are typically characterised by increased levels of income inequality. This study suggests that the twin burden of undernutrition and overnutrition in India is more likely to occur in high-inequality states. Focusing on economic equity via redistribution policies may have a substantial impact in reducing the prevalence of both undernutrition and overnutrition.
\end{abstract}

$\mathrm{T}$ he paradoxical co-occurrence of under- and overnutrition, and perhaps, more generally, the coexistence of diseases of poverty and affluence, is characteristic of rapidly developing economies. In recent years, considerable attention has been focused on documenting the rise in overweight and obesity in developing economies, ${ }^{1-3}$ and potential contributing factors that have been investigated include changes in the nature of work and transportation, the expansion of mass media and the increased consumption of energy-dense processed foods. ${ }^{4}$ At a fundamental level, the simultaneous presence of under- and overnutrition within a society is likely to reflect the differential distribution of resources at the individual level, i.e. some people do not have sufficient resources to meet their caloric requirements, while others have the resources to purchase their calorie requirements and more. Indeed, in the context of developing economies, there is considerable evidence to support the hypothesis that undernutrition is primarily concentrated among the poor while overnutrition is a problem among better-off groups, ${ }^{6}$ even though this social pattern is likely to change as countries attain a certain level of economic development. In the present study, we focus on a contextual variable - income inequality - that we hypothesise to be a predictor of the co-occurrence of under- and overnutrition. In addition to being an aggregate measure of the distribution of economic resources, income inequality has also been suggested as a marker of social cohesion. ${ }^{7}$ Socially cohesive communities have been hypothesised to be more generous in their provision of social safety nets, including the provision of food security. A study conducted in the United States reported that communitylevel social capital was significantly associated with a reduced risk of experiencing hunger among low-income individuals (adjusted odds ratio $(\mathrm{AOR})=0.47,95 \%$ CI 0.28 to 0.81 ), even after controlling for household socioeconomic status. ${ }^{8}$ Higher income inequality has also been linked to an increased risk of overweight and obesity (adjusted for individual income),? although inconsistent findings have also been reported. ${ }^{10}$

We hypothesised that, given the same level of income or socioeconomic position, an individual might be better off in a more egalitarian area, ${ }^{11}$ in terms of having a reduced risk both of being undernourished and of being overnourished. Specifically, we examine whether the contextual measure of income inequality measured at the level of the state in India (a rapidly developing economy, and one that is experiencing the double burden of under- and overnutrition) is independently predictive of under- and overnutrition in adult women. The health risks associated with overnutrition, ${ }^{12}$ as well as with chronic energy deficiency, ${ }^{13-18}$ are well known. Moreover, the combination of maternal undernutrition and overnutrition later in life is now believed to increase the risks of obesity, type II diabetes and cardiovascular disease. ${ }^{2} 1920$

\section{METHODS \\ Data}

The analyses are based on the representative cross-sectional 1998-99 Indian National Family Health Survey (INFHS) of 90303 women in 26 Indian states. ${ }^{21}$ The survey, which addressed various demographic and health aspects of women between the ages of 15 and 49, was conducted in one of the 18 Indian languages in respondents' homes and produced high response rates. $^{21}$ Women were geo-coded to the primary sampling unit, district and state to which they belong. The primary sampling units were villages or groups of villages in rural areas, and wards or municipal localities in urban areas. After restricting our sample to women for whom complete data 
were available on the outcome and predictors considered for the analysis, to women who were not pregnant and to women who were not attending school, our final sample for analysis comprised 77220 women. Table 1 shows categories of each of the variables considered in the study and the number and percentage of women in each group tabulated across five categories of body mass index.

\section{Outcome}

We used body mass index (BMI), calculated as weight in kilograms divided by height in metres squared $\left(\mathrm{kg} / \mathrm{m}^{2}\right)$, as the outcome for this study. Weight was measured using a solarpowered scale with an accuracy of $\pm 100 \mathrm{~g}$, while height was measured using an adjustable wooden measuring board, designed to provide accurate measurements (to the nearest $0.1 \mathrm{~cm}$ ) in the field in developing countries. ${ }^{22}$ Following World Health Organization (WHO) conventions, ${ }^{23}$ the following cutoff points of BMI (in $\mathrm{kg} / \mathrm{m}^{2}$ ) were adopted: < 18.5 (underweight), 18.5-22.9 (normal weight), 23-24.9 (at risk for overweight), 25-29.9 (overweight) and $\geqslant 30$ (obese). Given the identification of BMI $23 \mathrm{~kg} / \mathrm{m}^{2}$ as a public health cut-off point for risk of obesity in Asian populations, ${ }^{23}$ and the emerging evidence suggesting that lower cut-off points are appropriate for populations from the Indian subcontinent, ${ }^{24} 25$ we narrowed the "normal" BMI range of $18.5-24.9 \mathrm{~kg} / \mathrm{m}^{2}$ to $18.5-22.9 \mathrm{~kg} / \mathrm{m}^{2}$.

Table 2 shows the substantial between-state variation in the prevalence of undernutrition and the different categories of overnutrition. While the all-India prevalence of underweight was 33\%, it ranged from a low of $11 \%$ in Arunachal Pradesh to a high of $47 \%$ in Orissa. At the other extreme of the nutritional spectrum, 3\% of all Indian women were found to be obese, again with considerable variation between states, with Punjab having the highest prevalence ( $10 \%)$ of obesity and the states of Bihar and Mizoram the lowest, with only $0.5 \%$ of their population being classified as obese. Nationally, 10\% of women were overweight, with a range from 25\% (Delhi) to 3\% (Bihar). Some $9 \%$ of all women fell into the Asian-specific BMI category of "pre-overweight" or "at risk for overweight", again with substantial state-level variation, the figure ranging from $15 \%$ in Sikkim to $5 \%$ in Bihar. These results show that a high level of undernutrition often coexists with an appreciable prevalence of overnutrition, although there is considerable between-state variation, suggesting that there is a need to determine the statelevel factors that could account for this double burden of poor nutrition.

\section{Exposure}

We used the 1999-2000 state Gini coefficient of per capita consumption expenditure (estimated from the 55th round of the national survey of household consumer expenditure undertaken by the National Sample Survey Organization) as the measure of income inequality ${ }^{26}$ (Table 2). In most developing economies income is largely ascertained from expenditure data on various consumption-related items, and no direct income data are available on a routine basis. However, income measures based on consumption expenditure are very useful in developing countries; since households are both consumption and production units, not only is separating the two challenging, but such a distinction may be unrealistic from the perspective of the households. Consequently, focusing on expenditure provides direct insight into the overall economic standard of living. ${ }^{27}$ Moreover, given the lack of availability of income data for a majority of households, expenditure data allow for the "smoothing" of income fluctuations. This is especially important in developing economies, such as India, where the majority of the labour force is engaged in the agricultural sector or informal (unorganised) employment. Finally, consumption expenditure-based measures of income implicitly include non-monetary transactions, which may have a significant bearing on the economies of poor, backward rural areas and influence a person's or household's command over resources.

The 1999-2000 state Gini coefficients for per capita consumption expenditure were obtained from the 2001 National Human Development Report published by the Government of India (see table 2.3, p. 148). ${ }^{28}$ While there are different ways to measure inequality, Gini ratios are most commonly used to quantify the degree of inequality within a given community or society. ${ }^{29}$ Algebraically, the Gini coefficient is defined as half of the arithmetic average of the absolute differences between all pairs of incomes in a population, the total then being normalised on mean income. If incomes in a population are distributed completely equally, the Gini value is 0 (the condition of complete equality); if one person has all the income, the Gini coefficient is 1 (the condition of maximum inequality). ${ }^{30}$ The all-India average for the Gini ratio was 0.25 (median $=0.26$ ) with a standard deviation of 0.03 and range of 0.17 (Meghalaya) to 0.33 (Tamil Nadu) (Table 2).

\section{Covariates}

We considered a range of individual demographic, socioeconomic, behavioural and morbidity-related covariates (Table 1). Age was divided into 5-year ranges from age 15 to 49. Religious affiliation was categorised into Hindu, Muslim, Christian, Sikh and others. Marital status was defined as married or living with a partner, widowed or separated/ divorced. Caste was based on the women's self-identification as belonging to a scheduled caste, scheduled tribe, other backward class, other caste or no caste group. Scheduled tribe and scheduled caste are the most socially disadvantaged groups. Scheduled caste consists of castes that are lowest in the traditional Hindu caste hierarchy ${ }^{31}$ and as a consequence experiencing intense social and economic exclusion and disadvantage. Scheduled tribes comprise $\sim 700$ tribes which tend to be geographically isolated with limited economic and social interaction with the rest of the population. Other backward class is a diverse collection of "intermediate" castes that were considered low in the traditional caste hierarchy, but above scheduled castes. The "other" caste category is thus a default residual group that enjoys higher status in the caste hierarchy. We classified members of groups for which caste may not always be applicable (e.g. Muslims, Christians or Buddhists) and participants who did not report any caste affiliation in the survey as "no caste".

Socioeconomic measures included women's standard of living, educational status and current occupation. Standard of living was defined in terms of household assets and material possessions, which have been shown to be reliable and valid measures of household material well-being. ${ }^{32}$ Each woman was assigned a standard of living score that was based on a linear combination of the scores for different items that were recorded for the household in which the woman resided and weighted according to a "proportionate possession weighting" procedure. $^{33-35}$ The weighted scores were divided into quintiles for the analytical models. Women's educational status was measured as years of schooling. We adopted cut-off points for years of schooling based on typical education benchmarks: 0 (illiterate), 1-5 (primary), 6-8 (secondary), 9-12 (higher), 13-15 (college) and $>15$ years (postgraduate). Women's current occupation was defined as non-manual work (e.g. professional/managerial positions or clerical or sales or generally employed in the service sector); skilled or unskilled manual work (including paid household or domestic work); agricultural work either as an 
Table 1 Number and percentage of women in each category of the predictor variables according to body mass index (data from the 1998-99 Indian National Family Health Survey)

\begin{tabular}{|c|c|c|c|c|c|c|}
\hline \multirow[b]{3}{*}{ Variable } & \multirow[b]{3}{*}{ n (\%) } & \multicolumn{5}{|c|}{ Body mass index $\left(\mathrm{kg} / \mathrm{m}^{2}\right)$} \\
\hline & & \multirow{2}{*}{$\frac{<18.5}{n(\%)}$} & \multirow{2}{*}{$\frac{18.5-22.9}{n(\%)}$} & \multirow{2}{*}{$\frac{23-24.9}{n(\%)}$} & \multirow{2}{*}{$\frac{25-29.9}{n(\%)}$} & \multirow{2}{*}{$\frac{\geqslant 30}{n(\%)}$} \\
\hline & & & & & & \\
\hline All-India & $77220(100.0)$ & $24761(32.1)$ & $36102(46.8)$ & $\overline{6877(8.9)}$ & $7406(9.6)$ & $2074(2.7)$ \\
\hline \multicolumn{7}{|l|}{ Age (years) } \\
\hline $15-19$ & $4958(6.4)$ & $1954(39.4)$ & 2744 (55.3) & $180(3.6)$ & $76(1.5)$ & $4(0.1)$ \\
\hline $20-24$ & 12284 (15.9) & $4788(39.0)$ & $6408(52.2)$ & $641(5.2)$ & 396 (3.2) & $51(0.4)$ \\
\hline $25-29$ & 15339 (19.9) & 5393 (35.2) & 7464 (48.7) & 1240 & 1027 (6.7) & 215 (1.4) \\
\hline $30-34$ & 14124 (18.3) & $4323(30.6)$ & $6534(46.3)$ & $1381(9.8)$ & 1481 (10.5) & 405 (2.9) \\
\hline $35-39$ & 12535 (16.2) & $3437(27.4)$ & 5531 (44.1) & 1405 & 1652 (13.2) & $510(4.1)$ \\
\hline $40-44$ & 10115 (13.1) & $2793(27.6)$ & $4213(41.7)$ & 1116 (11.0) & 1539 & $454(4.5)$ \\
\hline $45-49$ & 7865 (10.2) & $2073(26.4)$ & $3208(40.8)$ & $914(11.6)$ & 1235 (15.7) & 435 (5.5) \\
\hline \multicolumn{7}{|l|}{ Religion } \\
\hline Hindu & $60311(78.1)$ & 20558 (34.1) & $27861(46.2)$ & 5103 & $5343(8.9)$ & $1446(2.4)$ \\
\hline Muslim & 8809 (11.4) & $2676(30.4)$ & $4064(46.1)$ & $828(9.4)$ & $952(10.8)$ & 289 (3.3) \\
\hline Christian & $4281(5.5)$ & $855(20.0)$ & $2381(55.6)$ & $469(11.0)$ & $472(11.0)$ & $104(2.4)$ \\
\hline Sikh & $1880(2.4)$ & $316(16.8)$ & $731(38.9)$ & 254 (13.5) & $413(22.0)$ & $166(8.8)$ \\
\hline Other & $1939(2.5)$ & 356 (18.4) & 1065 (54.9) & 223 (11.5) & $226(11.7)$ & $69(3.6)$ \\
\hline \multicolumn{7}{|l|}{ Caste } \\
\hline Other & 13055 (16.9) & 5208 (39.9) & $6033(46.2)$ & $873(6.7)$ & 776 (5.9) & 165 (1.3) \\
\hline Scheduled caste & 9220 (11.9) & 3150 (34.2) & $5028(54.5)$ & $598(6.5)$ & $373(4.0)$ & $71(0.8)$ \\
\hline Scheduled tribe & 22601 (29.3) & 7734 (34.2) & $10694(47.3)$ & $1893(8.4)$ & 1844 (8.2) & 436 (1.9) \\
\hline Other backward class & 31930 (41.3) & $8479(26.6)$ & $14158(44.3)$ & $3498(11.0)$ & 4396 (13.8) & $1399(4.4)$ \\
\hline No caste & $414(0.5)$ & $190(45.9)$ & $189(45.7)$ & $15(3.6)$ & $17(4.1)$ & $3(0.7)$ \\
\hline \multicolumn{7}{|l|}{ Marital status } \\
\hline Married & 72240 (93.6) & 23037 (31.9) & 33831 (46.8) & $6454(8.9)$ & 6955 (9.6) & $1963(2.7)$ \\
\hline Widow & $3341(4.3)$ & 1130 (33.8) & 1494 (44.7) & 303 & $334(10.0)$ & $80(2.4)$ \\
\hline Separated/divorced & $1639(2.1)$ & $594(36.2)$ & $777(47.4)$ & $120(7.3)$ & $117(7.1)$ & $31(1.9)$ \\
\hline \multicolumn{7}{|l|}{ Education (in years) } \\
\hline 0 & 38513 (49.9) & $15258(39.6)$ & 18654 (48.4) & $2348(6.1)$ & $1852(4.8)$ & $401(1.0)$ \\
\hline $1-5$ & 12977 (16.8) & $4167(32.1)$ & $6113(47.1)$ & $1169(9.0)$ & $1219(9.4)$ & $309(2.4)$ \\
\hline $6-8$ & 9668 (12.5) & $2535(26.2)$ & $4502(46.6)$ & 1080 & 1191 (12.3) & $360(3.7)$ \\
\hline $9-12$ & 12265 (15.9) & 2386 (19.5) & 5437 (44.3) & 1653 (13.5) & 2134 & 655 (5.3) \\
\hline $13-15$ & 2840 (3.7) & $722(25.4)$ & 1060 (37.3) & $463(16.3)$ & $742(26.1)$ & $250(8.8)$ \\
\hline$>15$ & $957(1.2)$ & $226(23.6)$ & $336(35.1)$ & 164 (17.1) & $268(28.0)$ & $99(10.3$ \\
\hline Standard of living index & & & & & & \\
\hline Bottom quintile & 12471 (16.1) & $6085(48.8)$ & $5751(46.1)$ & $421(3.4)$ & $187(1.5)$ & $27(0.2)$ \\
\hline Second quintile & $12900(16.7)$ & $5470(42.4)$ & 6349 (49.2) & $653(5.1)$ & $368(2.9)$ & $60(0.5)$ \\
\hline Third quintile & $15754(20.4)$ & $5689(36.1)$ & $7922(50.3)$ & 1158 (7.4) & $839(5.3)$ & $146(0.9)$ \\
\hline Fourth quintile & $17036(22.1)$ & 4505 (26.4) & $8368(49.1)$ & 1828 & 1889 (11.1) & $446(2.6)$ \\
\hline Top quintile & 19059 (24.7) & $3012(15.8)$ & $7712(40.5)$ & $2817(14.8)$ & $4123(21.6)$ & $1395(7.3)$ \\
\hline Occupation & & & & & & \\
\hline Homemaker & $48160(62.4)$ & $14024(29.1)$ & $22299(46.3)$ & $4755(9.9)$ & $5470(11.4)$ & $1612(3.3)$ \\
\hline Non-manual & 4433 (5.7) & 750 (16.9) & $1857(41.9)$ & 680 & $885(20.0)$ & $261(5.9)$ \\
\hline Agricultural work & $17758(23.0)$ & 7511 (42.3) & $8768(49.4)$ & $896(5.0)$ & $506(2.8)$ & $77(0.4)$ \\
\hline Manual & $6869(8.9)$ & $2476(36.0)$ & $3178(46.3)$ & $546(7.9)$ & 545 (7.9) & $124(1.8)$ \\
\hline Living environment & & & & & & \\
\hline Rural & 8620 (11.2) & $1411(16.4)$ & 3314 (38.4) & $1289(15.0)$ & $1917(22.2)$ & $689(8.0)$ \\
\hline Large city & $4995(6.5)$ & $1089(21.8)$ & 2010 (40.2) & 678 (13.6) & $910(18.2)$ & 308 (6.2) \\
\hline Small city & 10799 (14.0) & 2561 (23.7) & $4696(43.5)$ & 1363 (12.6) & 1676 (15.5) & $503(4.7)$ \\
\hline Town & $52806(68.4)$ & 19700 (37.3) & $26082(49.4)$ & $3547(6.7)$ & $2903(5.5)$ & 574 (1.1) \\
\hline Smoker & & & & & & \\
\hline No & 75139 (97.3) & 23925 (31.8) & 35071 (46.7) & $6758(9.0)$ & 7326 (9.7) & $2059(2.7)$ \\
\hline Yes & $2081(2.7)$ & $836(40.2)$ & $1031(49.5)$ & $119(5.7)$ & $80(3.8)$ & $15(0.7)$ \\
\hline Drinker & & & & & & \\
\hline No & 75012 (97.1) & 24071 (32.1) & $34827(46.4)$ & $6734(9.0)$ & 7326 (9.8) & 2054 (2.7) \\
\hline Yes & $2208(2.9)$ & $690(31.3)$ & 1275 (57.7) & $143(6.5)$ & $80(3.6)$ & $20(0.9)$ \\
\hline Chew tobacco & & & & & & \\
\hline No & $67927(88.0)$ & $21131(31.1)$ & $31658(46.6)$ & $6287(9.3)$ & $6883(10.1)$ & $1968(2.9)$ \\
\hline Yes & 9293 (12.0) & 3630 (39.1) & $4444(47.8)$ & $590(6.3)$ & $523(5.6)$ & $106(1.1)$ \\
\hline Tuberculosis & & & & & & \\
\hline No & 76782 (99.4) & 24515 (31.9) & $35939(46.8)$ & $6863(8.9)$ & 7394 (9.6) & 2071 (2.7) \\
\hline Yes & $438(0.6)$ & $246(56.2)$ & 163 (37.2) & $14(3.2)$ & $12(2.7)$ & $3(0.7)$ \\
\hline Malaria & & & & & & \\
\hline No & 74076 (95.9) & $23478(31.7)$ & $34618(46.7)$ & $6678(9.0)$ & 7265 (9.8) & $2037(2.7)$ \\
\hline Yes & $3144(4.1)$ & $1283(40.8)$ & 1484 (47.2) & $199(6.3)$ & $141(4.5)$ & $37(1.2)$ \\
\hline
\end{tabular}

employee or as an owner; or not currently participating in the labour force (including those not seeking work, such as homemakers).

Other covariates included women's residential living environment, which was characterised according to whether the household in which the woman resided is located in a large city (population $\geqslant 1$ million), a small city (population, $100000-1$ million), a town (population $\leqslant 100000$ ) or in a village or rural area. Health behaviours included self-reported current smoking, alcohol use and tobacco chewing. Parity in terms of 
Table 2 Distribution of women in different body mass index categories and distribution of state-level variables in 26 Indian states

\begin{tabular}{|c|c|c|c|c|c|c|c|c|c|}
\hline \multirow[b]{2}{*}{ State } & \multirow[b]{2}{*}{$n$} & \multicolumn{5}{|c|}{$\begin{array}{l}\text { Percentage of women with body mass index } \\
\left(\mathrm{kg} / \mathrm{m}^{2}\right)\end{array}$} & \multirow[b]{2}{*}{ PCNSDP* } & \multirow[b]{2}{*}{ PCCE } & \multirow[b]{2}{*}{ Gini } \\
\hline & & $<18.5$ & $18.5-22.9$ & $23-24.9$ & $25-29.9$ & $9 \geqslant 30$ & & & \\
\hline All India & 77220 & 32.1 & 46.8 & 8.9 & 9.6 & 2.7 & 2840 & 590.98 & 0.29 \\
\hline Andhra Pradesh & 3761 & 37.1 & 42 & 8.6 & 10 & 2.3 & 2550 & 550.53 & 0.27 \\
\hline Assam & 2866 & 25.9 & 60.2 & 8.2 & 4.7 & 0.9 & 1675 & 473.42 & 0.26 \\
\hline Bihar & 6129 & 39.5 & 52 & 4.9 & 3.1 & 0.5 & 1126 & 417.18 & 0.26 \\
\hline Goa & 1134 & 27.4 & 38.4 & 13.2 & 16.6 & 4.4 & 5640 & 1014.78 & 0.26 \\
\hline Gujarat & 3427 & 37.3 & 37.3 & 9.6 & 11.4 & 4.4 & 3918 & 678.27 & 0.26 \\
\hline Haryana & 2628 & 26.2 & 47.9 & 9.6 & 12.4 & 3.8 & 4025 & 767.89 & 0.26 \\
\hline Himachal Pradesh & 2797 & 27.3 & 45 & 10.6 & 13.5 & 3.6 & 2556 & 737.82 & 0.27 \\
\hline Jammu & 2441 & 25.1 & 48.4 & 11.2 & 11.9 & 3.4 & 1932 & 746.74 & 0.20 \\
\hline Karnataka & 3912 & 39.5 & 39 & 7.9 & 10.7 & 2.9 & 2866 & 638.81 & 0.28 \\
\hline Kerala & 2617 & 18.3 & 45.4 & 15.2 & 17.2 & 3.9 & 2490 & 816.76 & 0.30 \\
\hline Madhya Pradesh & 6106 & 36.6 & 50.7 & 6.3 & 5.2 & 1.2 & 1922 & 478.92 & 0.28 \\
\hline Maharashtra & 4796 & 33.8 & 38.5 & 10.1 & 13.1 & 4.5 & 5032 & 697.42 & 0.30 \\
\hline Manipur & 1267 & 19.1 & 58.6 & 11.7 & 9.5 & 1.1 & 1948 & 596.36 & 0.20 \\
\hline Meghalaya & 677 & 25.4 & 60.7 & 8.1 & 4.6 & 1.2 & 1804 & 639.13 & 0.18 \\
\hline Mizoram & 922 & 21.8 & 64.9 & 8 & 4.8 & 0.5 & 2840 & 935.53 & 0.21 \\
\hline Nagaland & 676 & 18.3 & 60.7 & 12.4 & 7.8 & 0.7 & 2164 & 1005.99 & 0.18 \\
\hline Orissa & 4022 & 47.0 & 42.5 & 5.4 & 4.4 & 0.8 & 1666 & 413.71 & 0.27 \\
\hline Punjab & 2535 & 16.5 & 38.9 & 13.3 & 21.7 & 9.6 & 4389 & 792.07 & 0.26 \\
\hline Rajasthan & 5696 & 36.4 & 50.5 & 6.3 & 5.2 & 1.5 & 2226 & 611.19 & 0.25 \\
\hline Sikkim & 949 & 11.0 & 58.8 & 15.4 & 12.4 & 2.4 & 3461 & 559.97 & 0.24 \\
\hline Tamil Nadu & 4252 & 27 & 44.8 & 11.7 & 13.4 & 3.1 & 3141 & 681.37 & 0.34 \\
\hline West Bengal & 3882 & 38.9 & 39.7 & 8.6 & 10.6 & 2.3 & 2977 & 571.66 & 0.28 \\
\hline Uttar Pradesh & 5736 & 36.3 & 49.5 & 6.9 & 5.8 & 1.5 & 1725 & 516.99 & 0.29 \\
\hline New Delhi & 2070 & 12.3 & 37.8 & 16 & 24.6 & 9.2 & 6478 & 1316.3 & 0.25 \\
\hline Arunachal Pradesh & 951 & 10.9 & 76.8 & 7 & 4.6 & 0.6 & 3571 & 672.31 & 0.30 \\
\hline Tripura & 971 & 35.6 & 47.1 & 9.5 & 6.1 & 1.8 & 2117 & 589.5 & 0.24 \\
\hline
\end{tabular}

children ever born to women was also included as a predictor of nutritional status. Self-reported current morbidities associated with malaria and whether the respondent was receiving treatment for tuberculosis were also included.

We also adjusted models for the overall level of economic development of the state, by including two separate measures: (i) the 1999-2000 average per capita consumption expenditure (PCCE) (in Indian rupees, INR) and (ii) the 1997-98 per capita net state domestic product (PCSDP) (INR at 1980-81 prices); both were obtained from the 2001 National Human Development Report (tables 2.1 and 2.2, pp. 146-7). ${ }^{28}$ While data on PCCE were available for all the states, data on PCSDP were not available for Mizoram, for which we imputed the overall Indian average. For the states of Sikkim and Nagaland we used the 1993-94 PCSDP as data for 1997-98 were not available. ${ }^{28}$ The all-India PCSDP in 1998-99 was 2840 INR, with a range of 1126 INR (Bihar) to 6478 INR (Delhi). The all-India PCCE in 1999-2000 was 591 INR, with a range of 414 INR (Orissa) to 1015 INR (Goa). While the two measures capture approximately the same construct of aggregate economic well-being, there remain important differences in the ways these measures are constructed. ${ }^{36}{ }^{37}$ Typically, higher PCSDP and PCCE are associated with higher levels of economic development, and the two measures exhibit a high degree of correlation $(\mathrm{r}=0.70, \mathrm{p}<0.0001)$. Since complete data were available for PCCE, the results presented in the tables and the figure are based upon models that used PCCE as the control. However, in the results section we also report the results for Gini coefficient when we consider PCSDP as a control. Meanwhile, PCSDP and PCCE were not correlated with the Gini coefficient $(\mathrm{r}=0.24, \mathrm{p}=0.23$, and $\mathrm{r}=-0.22, \mathrm{p}=0.27$, respectively $)$.

\section{Statistical analysis}

Given the multilevel structure of the sample with an explicit interest in modelling the effects of state-level exposure and with the individual outcome consisting of multiple categories, a multilevel multinomial modelling approach was adopted. ${ }^{38-40}$ Formally, $y_{i j k l}$ is the categorical outcome with $t$ categories, for woman $i$ in primary sampling unit $j$ in district $k$, state $l$. We denote the probability of being in category $s$ by $\pi_{i j k l}^{(s)}=\operatorname{Pr}\left(y_{i j k l}=s\right)$. In a multinomial logistic model, one of the outcome categories is taken as the reference categories, just as the category coded " 0 " is usually taken as the "reference" category in more commonly used binary response models. Using the BMI category of $18.5-22.9 \mathrm{~kg} / \mathrm{m}^{2}$ as the reference, we estimated a simultaneous set of $t-1$ logistic regression for the undernutrition and three overnutrition categories, contrasting each of the categories with the reference category, and specifying a multilevel multinomial logistic regression model with logit link:

$$
\log \left(\frac{\pi_{i j k l}^{(s)}}{\pi_{i j k l}^{(t)}}\right)=\beta^{(s)} X_{+}\left(u_{j k l}^{(s)}+v_{k l}^{(s)}+f_{1}^{(s)}\right), \quad s=1, \ldots, t-1
$$

A separate intercept and slope parameter was estimated for the undernutrition and three overnutrition categories, as indicated by the $s$ superscripts. The notation $\beta^{(s)}$ represents the fixed part of the model, and is interpreted as the effect of a 1 -unit increase in $X$ (the set of independent variables) on the $\log$ odds of being in category $s$ (i.e. the undernutrition or one of the three overnutrition categories) compared with category $t$ (the "normal" BMI category). For presentation and discussion, we used $\exp \left(\beta^{(s)}\right)$, which is the effect of a unit increase in $X$ on the odds of being in category $s$ rather than category $t$. The terms inside the brackets in equation $(1), u_{j k l}^{(s)}, v_{k l}^{(s)}$ and $f_{l}^{(s)}$ represent the random effects associated with primary sampling units, districts and states, respectively, assumed to be normally 
distributed with mean 0 and variances, $\sigma_{u \prime}^{(s)} \sigma_{v}^{(s)}$ and $f_{l}^{(s)}$. The random effects are specific to each of the contrasted category, as indicated by the $s$ superscript, because different unobserved factors, at each level, may affect each contrast. We allow for the possible correlation in the random effects at each level across different contrasts. Regression and variance parameters are based on penalised quasi-likelihood estimation, with secondorder Taylor series linearisation. ${ }^{3841}$

\section{RESULTS}

Table 3 presents the mutually adjusted odds ratios (ORs) and the $95 \%$ confidence intervals (CIs) for the risk of being underweight, pre-overweight, overweight and obese for the exposure variable and the covariates, using the normal BMI category as the reference. State-level income inequality was strongly associated with the levels of BMI $(p<0.0001)$, even after controlling for a range of individual and state-level covariates. As shown in Figure 1, a one-standard deviation increase in Gini coefficient (which corresponds to approximately a 3\% change in the Gini coefficient) increased the OR for being underweight by 1.19 (95\% CI 1.03 to 1.37). The risk of being obese also increased by $21 \%$ (95\% CI 1.13 to 1.29 ) for a one-standard deviation change in the Gini coefficient. The effect of Gini coefficient on the risk of being overweight was similar to that for obesity (OR 1.19, 95\% CI 1.04 to 1.37 ). The Gini coefficient was also positively associated with the risk of being pre-overweight (OR 1.09, 95\% CI 1.05 to 1.13 ). When we considered PCSDP as a control variable, instead of PCCE, the results were largely similar: a one-standard deviation increase in Gini coefficient increased the odds ratio for being underweight by 1.19 (95\% CI 1.02 to 1.39). The OR of being obese increased by $10 \%$ (95\% CI 1.04 to 1.18 ) for a one-standard deviation increase in the Gini coefficient. The effect of Gini coefficient on the risk of being overweight was similar to that for obesity, except that the estimate had lower statistical precision. The Gini coefficient was also positively associated with the risk of being pre-overweight.

We conducted additional tests of interaction (not reported) between state Gini coefficient and women's standard of living index to verify if the effect of state Gini coefficient was confined to specific socioeconomic groups, but we did not find support for this hypothesis. We also considered models in which the state Gini coefficient measured in 1993-94 was used and obtained results similar to those reported here. Indeed, the correlation between state Gini coefficient in the two periods (1993-94 and 1999-00) was 0.78.

Other notable results included the strong positive association between state per capita consumption expenditure and risk of being pre-overweight (OR 1.12, 95\% 1.09 to 1.16), overweight (OR 1.18, 95\% 1.02 to 1.36 ) and obese (OR 1.24, 95\% 1.19 to 1.30), with the ORs expressing one standard deviation increase in state per capita consumption expenditure (Table 3). However, increases in state per capita consumption expenditure did not substantially decrease the risk of being underweight and the relationship was statistically insignificant (OR 0.96, 95\% CI 0.83 to 1.13 ). These associations were largely similar when we considered state average per capita net state domestic product. At the individual level, socioeconomic position was a strong predictor of body mass index: on average, higher levels of education or standard of living decreased the risk of being undernourished and increased the risk of being overnourished (Table 3).

\section{DISCUSSION}

This analysis found an association between state income inequality and levels of nutritional status, as measured by BMI, even after adjusting for a range of individual and state- level covariates in India. The adverse contextual effect of state income inequality is observed for the risk of being underweight as well as for each of the categories that characterise overnutrition (i.e. pre-overweight, overweight and obese). It is important to emphasise that what we report is a contextual effect of income inequality, after adjusting for individual-level factors, including economic standard of living, which we know has a clear relationship to nutritional status (in that women of low socioeconomic status experience the greatest risk for underweight and those in high socioeconomic status experience the greatest risk for being pre-overweight, overweight and obese $)^{62-44}$, a pattern also observed in this study. Thus, the context of inequality seems to accentuate the income-based disparities in consumption (reflected in people's BMI).

Why should income inequality be adversely associated with both undernutrition and overnutrition? An insightful analogy can be drawn with the causes of famines. Famines, as we now understand, are caused not so much by a shortage of food as by the maldistribution of food. ${ }^{45}$ In a similar manner, the simultaneous presence of under- and overnutrition probably reflects the maldistribution of resources in food and as well other domains of critical importance to nutritional status. Thus, highly unequal states are characterised by the simultaneous existence of overconsumption by privileged groups and food insecurity among the poor. In addition to being an indicator of maldistributed resources, income inequality may also be a marker of a less generous, or inefficient, public distribution system, e.g. as a result of corruption. ${ }^{7}$ For instance, it has been shown that the non-poor are more likely than the poor to use public systems designed to provide shelter, water, sanitation and sewerage, health care and food grains, ${ }^{46}$ suggesting that public distribution systems in many communities are poorly designed to meet the needs of the poor, a necessary condition for overcoming the burden of undernutrition. At the same time, it is likely that existing public distribution systems are vulnerable to manipulation by vested interests, a characteristic more likely to be present in states with high levels of income inequality and low social cohesion.

Indeed, there is evidence to suggest that one of the flagship programmes aimed at improving nutrition of children and mothers - the Integrated Child Development Scheme (ICDS) is regressive in several ways. ${ }^{47}$ First, coverage of the programme is highest in states with the lowest levels of undernutrition. Second, coverage of the ICDS programme tends to be higher in states with high economic growth. Finally, in the poorer states, government budgetary allocations for the ICDS programme per undernourished child is lower. Indeed, poorer states also tend to spend only $65-75 \%$ of their allocation, suggesting poor

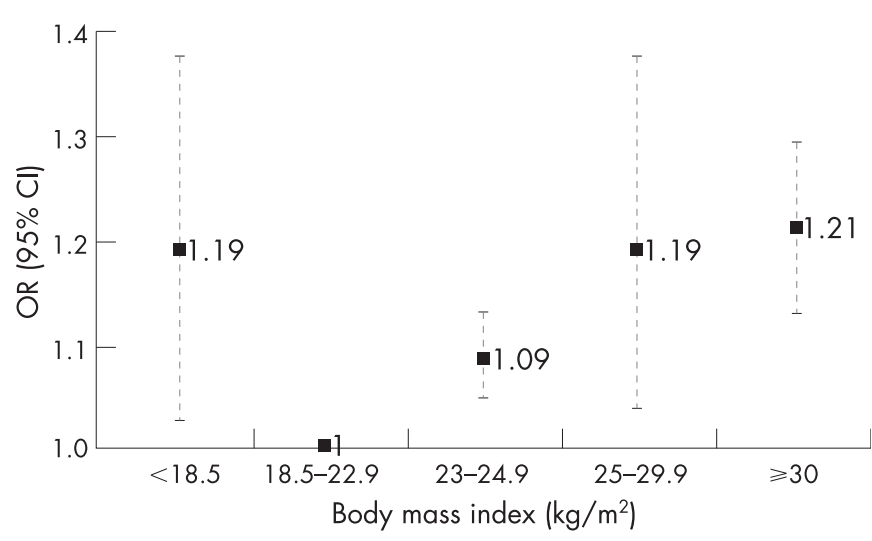

Figure 1 Plot showing the odds ratios (ORs) and 95\% confidence interval (CI) for one-standard deviation change in Gini coefficient for the risk of being underweight, pre-overweight, overweight and obese. 
Table 3 Mutually adjusted odds ratios (ORs) and 95\% confidence interval (CI) from the fixed part of unordered multinomial multivariable model (using BMI $18.5-22.9 \mathrm{~kg} / \mathrm{m}^{2}$ as the reference) conditional on the random effects associated with primary sampling units, districts and states

\begin{tabular}{|c|c|c|c|c|}
\hline & \multicolumn{4}{|c|}{ Body mass index $\left(\mathrm{kg} / \mathrm{m}^{2}\right)$} \\
\hline & $<18.5$ & \multirow{2}{*}{$\frac{23-24.9}{\text { OR }(95 \% \mathrm{Cl})}$} & \multirow{2}{*}{$\begin{array}{l}25-29.9 \\
\text { OR }(95 \% \mathrm{Cl})\end{array}$} & \multirow{2}{*}{$\begin{array}{l}\geqslant 30 \\
\text { OR }(95 \% \mathrm{Cl})\end{array}$} \\
\hline & OR $(95 \% \mathrm{Cl})$ & & & \\
\hline \multicolumn{5}{|l|}{ State income inequality } \\
\hline Gini coefficient & 1.19 (1.03 to 1.37$)$ & 1.09 (1.05 to 1.13$)$ & 1.19 (1.04 to 1.37 ) & $1.21(1.13$ to 1.29$)$ \\
\hline \multicolumn{5}{|l|}{ Age (years) } \\
\hline $15-19$ & 1.00 & 1.00 & 1.00 & 1.00 \\
\hline $20-24$ & 1.15 (1.07 to 1.23 ) & 1.25 (1.05 to 1.48$)$ & 1.44 (1.13 to 1.83$)$ & $3.13(1.16$ to 8.43$)$ \\
\hline $25-29$ & $1.10(1.02$ to 1.19$)$ & 2.11 (1.79 to 2.48 ) & 3.09 (2.45 to 3.89$)$ & 11.02 (4.20 to 28.95$)$ \\
\hline $30-34$ & 0.96 (0.89 to 1.04$)$ & $2.80(2.37$ to 3.30$)$ & $5.29(4.19$ to 6.68$)$ & $24.70(9.44$ to 64.69$)$ \\
\hline $35-39$ & $0.88(0.81$ to 0.95$)$ & 3.55 (3.00 to 4.20$)$ & 7.47 (5.91 to 9.44$)$ & 41.64 (15.90 to 109.02$)$ \\
\hline $40-44$ & 0.90 (0.83 to 0.99$)$ & 3.75 (3.15 to 4.45$)$ & $9.12(7.20$ to 11.56$)$ & $48.57(18.51$ to 127.42$)$ \\
\hline $45-49$ & $0.88(0.80$ to 0.96$)$ & 4.15 (3.47 to 4.96 ) & 9.76 (7.67 to 12.41$)$ & $63.62(24.21$ to 167.18$)$ \\
\hline \multicolumn{5}{|l|}{ Religion } \\
\hline Hindu & 1.00 & 1.00 & 1.00 & 1.00 \\
\hline Muslim & 1.04 (0.98 to 1.11$)$ & 1.22 (1.12 to 1.33 ) & 1.36 (1.24 to 1.49$)$ & 1.66 (1.45 to 1.91$)$ \\
\hline Christian & 0.81 (0.72 to 0.90$)$ & $1.07(0.95$ to 1.21$)$ & $1.13(0.99$ to 1.29$)$ & 0.91 (0.73 to 1.14 ) \\
\hline Sikh & $0.97(0.81$ to 1.14$)$ & 1.19 (1.04 to 1.37$)$ & 1.27 (1.08 to 1.49 ) & $2.12(1.78$ to 2.53$)$ \\
\hline Other & $0.80(0.70$ to 0.91$)$ & 1.39 (1.19 to 1.61$)$ & $1.42(1.21$ to 1.67$)$ & 1.64 (1.28 to 2.11$)$ \\
\hline \multicolumn{5}{|l|}{ Caste } \\
\hline Other & 1.00 & 1.00 & 1.00 & 1.00 \\
\hline Scheduled caste & $1.14(1.08$ to 1.20$)$ & 0.90 (0.83 to 0.98$)$ & 0.80 (0.73 to 0.88$)$ & $0.66(0.56$ to 0.78$)$ \\
\hline Scheduled tribe & $0.98(0.91$ to 1.05$)$ & $0.88(0.79$ to 0.99$)$ & $0.78(0.68$ to 0.90$)$ & $0.61(0.46$ to 0.80$)$ \\
\hline Other backward class & 1.05 (1.00 to 1.10$)$ & 1.00 (0.93 to 1.06$)$ & $0.87(0.82$ to 0.94$)$ & 0.78 (0.69 to 0.88 ) \\
\hline No caste & $1.17(0.95$ to 1.45$)$ & $0.61(0.36$ to 1.02$)$ & $0.84(0.52$ to 1.36$)$ & $0.51(0.16$ to 1.67$)$ \\
\hline \multicolumn{5}{|l|}{ Marital status } \\
\hline Married & 1.00 & 1.00 & 1.00 & 1.00 \\
\hline Widow & 1.05 (0.97 to 1.13 ) & $0.97(0.85$ to 1.10$)$ & 0.95 (0.84 to 1.07$)$ & $0.79(0.63$ to 1.00$)$ \\
\hline Separated/divorced & 1.11 (1.00 to 1.24$)$ & $0.87(0.72$ to 1.06$)$ & $0.89(0.73$ to 1.09$)$ & $0.89(0.61$ to 1.31$)$ \\
\hline \multicolumn{5}{|l|}{ Education (years) } \\
\hline 0 & 1.00 & 1.00 & 1.00 & 1.00 \\
\hline $1-5$ & 0.98 (0.94 to 1.03 ) & 1.17 (1.08 to 1.26$)$ & 1.26 (1.16 to 1.37$)$ & 1.34 (1.15 to 1.56$)$ \\
\hline $6-8$ & $0.93(0.88$ to 0.99$)$ & 1.34 (1.23 to 1.45$)$ & 1.45 (1.33 to 1.58$)$ & $1.70(1.46$ to 1.99$)$ \\
\hline $9-12$ & 0.85 (0.80 to 0.91$)$ & 1.39 (1.28 to 1.51$)$ & $1.60(1.47$ to 1.75$)$ & 1.74 (1.49 to 2.03$)$ \\
\hline $13-15$ & 0.75 (0.66 to 0.86$)$ & 1.41 (1.24 to 1.60$)$ & 1.76 (1.56 to 1.99$)$ & 1.86 (1.52 to 2.27$)$ \\
\hline$>15$ & $0.72(0.57$ to 0.90$)$ & 1.44 (1.19 to 1.75$)$ & 1.84 (1.54 to 2.19$)$ & 2.26 (1.74 to 2.94$)$ \\
\hline Standard of living index & & & & \\
\hline Bottom quintile & 1.00 & 1.00 & 1.00 & 1.00 \\
\hline Second quintile & $0.91(0.87$ to 0.96$)$ & 1.27 (1.12 to 1.44$)$ & 1.40 (1.18 to 1.66$)$ & 1.52 (0.97 to 2.38$)$ \\
\hline Third quintile & $0.86(0.81$ to 0.90$)$ & 1.57 (1.39 to 1.76$)$ & 1.95 (1.67 to 2.29 ) & 2.08 (1.38 to 3.13 ) \\
\hline Fourth quintile & $0.67(0.64$ to 0.72$)$ & 1.80 (1.60 to 2.02$)$ & $2.80(2.40$ to 3.27$)$ & 3.44 (2.32 to 5.11$)$ \\
\hline Top quintile & 0.53 (0.49 to 0.57$)$ & 2.27 (2.00 to 2.56$)$ & 4.32 (3.69 to 5.06 ) & 6.40 (4.30 to 9.51$)$ \\
\hline Occupation & & & & \\
\hline Homemaker & 1.00 & 1.00 & 1.00 & 1.00 \\
\hline Non-manual & 0.85 (0.78 to 0.93 ) & 1.12 (1.01 to 1.23 ) & $1.00(0.92$ to 1.10$)$ & 0.89 (0.77 to 1.04 ) \\
\hline Agricultural work & 1.05 (1.00 to 1.10$)$ & $0.74(0.68$ to 0.80$)$ & $0.53(0.47$ to 0.58$)$ & $0.42(0.33$ to 0.53$)$ \\
\hline Manual & 1.05 (0.99 to 1.12$)$ & $0.84(0.77$ to 0.93$)$ & $0.76(0.69$ to 0.84$)$ & 0.65 (0.53 to 0.78$)$ \\
\hline Living environment & & & & \\
\hline Rural & 1.00 & 1.00 & 1.00 & 1.00 \\
\hline Large city & 0.84 (0.75 to 0.95$)$ & 1.54 (1.42 to 1.67$)$ & 1.93 (1.72 to 2.17$)$ & 2.89 (2.53 to 3.30$)$ \\
\hline Small city & 0.85 (0.78 to 0.94$)$ & 1.49 (1.36 to 1.64$)$ & 1.78 (1.60 to 1.98$)$ & $2.68(2.31$ to 3.12$)$ \\
\hline Town & $0.90(0.84$ to 0.96$)$ & 1.36 (1.27 to 1.46$)$ & 1.58 (1.46 to 1.71$)$ & 2.08 (1.82 to 2.36$)$ \\
\hline Parity & & & & \\
\hline No children & 1.00 & 1.00 & 1.00 & 1.00 \\
\hline Children & 1.02 (1.01 to 1.03 ) & $0.97(0.96$ to 0.99$)$ & 0.99 (0.97 to 1.01$)$ & 0.98 (0.95 to 1.01$)$ \\
\hline Smoking & & & & \\
\hline No & 1.00 & 1.00 & 1.00 & 1.00 \\
\hline Yes & $1.33(1.20$ to 1.46$)$ & $0.79(0.65$ to 0.96$)$ & $0.69(0.55$ to 0.86$)$ & $0.57(0.34$ to 0.96$)$ \\
\hline Drinking & & & & \\
\hline No & 1.00 & 1.00 & 1.00 & 1.00 \\
\hline Yes & $0.86(0.78$ to 0.96$)$ & 1.14 (0.95 to 1.37$)$ & $0.81(0.62$ to 1.04$)$ & 1.31 (0.82 to 2.08$)$ \\
\hline Chew tobacco & & & & \\
\hline No & 1.00 & 1.00 & 1.00 & 1.00 \\
\hline Yes & 1.15 (1.09 to 1.21$)$ & $0.77(0.70$ to 0.85$)$ & 0.88 (0.79 to 0.97$)$ & $0.61(0.50$ to 0.75$)$ \\
\hline Tuberculosis & & & & \\
\hline No & 1.00 & 1.00 & 1.00 & 1.00 \\
\hline Yes & $2.13(1.75$ to 2.60$)$ & $0.45(0.27$ to 0.77$)$ & $0.40(0.23$ to 0.71$)$ & 0.35 (0.11 to 1.10$)$ \\
\hline Malaria & & & & \\
\hline No & 1.00 & 1.00 & 1.00 & 1.00 \\
\hline Yes & 1.12 (1.03 to 1.21$)$ & $0.96(0.82$ to 1.11$)$ & $0.84(0.71$ to 0.99$)$ & 0.93 (0.68 to 1.27$)$ \\
\hline State economic development & & & & \\
\hline PCCE & 0.96 (0.83 to 1.13$)$ & 1.12 (1.09 to 1.16$)$ & 1.18 (1.02 to 1.36$)$ & 1.24 (1.19 to 1.30$)$ \\
\hline
\end{tabular}


governance. The regressive nature of this programme increased in the 1990s. ${ }^{47}$ Thus, it is possible that there may be other contextual features of high-inequality states that make the goal of eliminating undernutrition difficult.

The fact that, on average, coverage of the ICDS programme tends to be greater in the richer states has led to the hypothesis that economic growth may eventually lead to a reduction in undernutrition through a trickle-down mechanism. However, in our analysis we could find only partial support for this. For instance, although women in richer states were more likely to be overnourished, there was no evidence that in these states the risk for underweight was actually lower than in states with considerably lower levels of economic growth. In a previous study, it was reported that for women in richer states the risk of being underweight increased for those in the lowest quintile of standard of living and decreased for those in the highest quintile. ${ }^{6}$ This again suggest that the health dividends of aggregate economic development seem to accrue largely to better-off sections of the population.

The following caveats should be borne in mind when considering our study findings. BMI was the only measure of nutritional status available. While a low level of BMI is likely to be a valid proxy for chronic energy deficiency in an individual, BMI does not adequately correlate with measures of body fat, which, for any value of BMI, may be higher in Indians than in other populations. ${ }^{48}{ }^{49}$ Thus, for any given BMI, the risk for the consequences of obesity, such as diabetes and cardiovascular disease, may be greater among Indians than in the populations on which BMI standards were initially developed. ${ }^{50}$ These factors may limit the ability of our study to estimate the true burden of chronic diseases and mortality associated with undernutrition and overnutrition; however, in the Indian context, women's BMI may have particular relevance because of its impact on the health of their offspring. Women of low pre-pregnancy BMI have lower-birthweight babies, ${ }^{51}$ and the evidence that low birthweight and low maternal BMI are associated with increased risk of adulthood chronic disease among offspring is consistent and universal. ${ }^{52}$ Indeed, the coexistence of undernutrition and overnutrition in India also means that the consequences of maternal obesity - high birthweight and a higher risk of diabetes among offspring - will increasingly be seen. ${ }^{52}$ As Osmani and Sen point out, ${ }^{20}$ gender inequality can contribute to the intergenerational transmission of poor health through poor intrauterine and early life course exposures. It should also be noted that our findings relate to ever-married women between the ages of 15 and 49, even though it has the advantage of being nationally representative. However, the patterns observed in this study with regards to the relationship between nutritional status and individual covariates (including socioeconomic position) is consistent with prior studies on women and men, ${ }^{42-44}$ thus strengthening the general relevance of our findings.

In conclusion, our study has shown an association between state income inequality and the concurrent presence of risk of individual underweight and overweight. Focusing on overall economic equity - especially during phases of health and economic transition - is likely to address this dual burden.

\section{ACKNOWLEDGEMENTS}

$\mathrm{S} V$ Subramanian is supported by the National Institutes of Health Career Development Award (NHLBI 1 K25 HL081275). We thank Richard Wilkinson for helpful comments.

\section{CONTRIBUTIONS}

S V Subramanian conceived the study, designed the analysis, interpreted the results and wrote and edited the manuscript. Ichiro Kawachi and George Davey Smith contributed to the interpretation of the results and writing and editing of the manuscript.

\section{What is already known on this subject}

The double burden of undernutrition and overnutrition, which is characteristic of rapidly developing economies, is increasingly being recognised. However, the macroeconomic determinants of this double burden have to date not been systematically investigated.

\section{What this study adds}

We found that the risk of under- and the risk of overnutrition at the individual level tended to be particularly high in states with high income inequality, after adjusting for various individual covariates as well as state economic development.

\section{Policy implications}

Complementing strategies of accelerating economic growth with measures focused on ensuring economic equity is likely to optimise health outcomes in rapidly developing economies.

\section{Authors' affiliations}

S V Subramanian, Ichiro Kawachi, School of Public Health, Harvard University

George Davey Smith, Department of Social Medicine, University of Bristol

\section{REFERENCES}

1 Mendez MA, Monteiro CA, Popkin BM. Overweight exceeds underweight among women in most developing countries. Am J Clin Nutr 2005;81:714-21.

2 Caballero B. Obesity in developing countries: biological and ecological factors. J Nutr 2001;131:866-70S.

3 Monteiro CA, Conde WL, Lu B. et al, Obesity and inequities in health in the developing world. Int J Obes, 2004;28:1181-6.

4 Popkin BM, Horton S, Kim S, et al. Trends in diet, nutritional status, and dietrelated noncommunicable diseases in China and India: the economic costs of nutrition transition. Nutr Rev 2001;59:379-90.

5 Popkin BM. The nutrition transition in the developing world. Development Policy Review 2003;21:581-97.

6 Subramanian SV, Davey Smith G. Patterns, distribution and determinants of under and overnutrition: a population-based study of women in India. Am J Clin Nutr 2006;84:633-40.

7 Easterly W, Ritzen J, Woolcock M. Social cohesion, institutions and growth. New York: Development Research Institute, New York University, 2005.

8 Martin KS, Rogers BL, Cook JT, et al. Social capital is associated with decreased risk of hunger. Soc Sci Med 2004;58:2645-54.

9 Diez-Roux AV, Link BG, Northridge ME. A multilevel analysis of income inequality and cardiovascular disease risk factors. Soc Sci Med 2000;50:673-87.

10 Chang VW, Christakis NA. Income inequality and weight status in US metropolitan areas. Soc Sci Med 2005;61:83-96.

11 Kawachi I, Kennedy BP. The health of nations. New York: The New Press, 2003.

12 Haslam DW, James WPT, Obesity. Lancet 2005;366:1197-209.

13 Ferro-Luzzi A, Sette S, Franklin M, et al. A simplified approach to assessing adult energy deficiency. Eur J Clin Nutr 1992;46:173-86.

14 WHO. Physical status: the use and interpretation of anthropometry. World Health Organization: Geneva, 1995.

15 Naidu NA, Rao PN. Body mass index: a measure of nutritional status in Indian population. Eur J Clin Nutr 1994;48:S131-40.

16 Report N. Body mass index and mortality rates - a 10 year perspective study. Hyderabad: National Institute of Nutrition, 1990.

17 Hosegood V, Campbell OMR. Body mass index, height, weight, arm circumference and mortality in rural Bangladeshi women: a 19-y longitudinal study. Am J Clin Nutr 2003;77:341-7.

18 Thomas D, Frankenberg E. Health, nutrition and economic prosperity: a microeconomic perspective. Los Angeles: California Center for Population Research, University of California, 2002.

19 Barker DJP. The effects of nutrition of the foetus and neonate on cardiovascular disease in later life. Proc Nutr Soc 1992;51:135-44.

20 Osmani S, Sen A. The hidden penalties of gender inequality: fatal origins of illhealth. Econ Hum Biol 2003;1:105-21. 
21 IIPS, National Family Health Survey 1998-99. Mumbai: International Institute of Population Sciences, 2000.

22 Mishra V. Effect of obesity on asthma among adult Indian women. Int J Obes 2004;28:1048-58.

23 WHO. Expert Consultation: Appropriate body mass index for Asian populations and its implications for policy and intervention strategies. Lancet 2004;363:157-63.

24 Razak F, Anand S, Vuksan V, et al. Ethnic differences in the relationships between obesity and glucose-metabolic abnormalities: a cross-sectional population-based study. Int J Obes 2005;29:656-67.

25 Misra A, Vikram NK, Gupta R, et al. Waist circumference cutoff points and action levels for Asian Indians for identification of abdominal obesity. Int J Obes 2006;30:106-11

26 NSSO, Household consumer expenditure (55th round). New Delhi: National Sample Survey Organization, Central Statistical Organization, 2000.

27 Deaton A. The analysis of household surveys. Baltimore: Johns Hopkins University Press, 1997.

28 Government of India. National Human Development Report 2001. New Delhi: Planning Commission, Government of India, 2002.

29 Kawachi I, Kennedy BP. The relationship of income inequality to mortality - does the choice of indicator matter? Soc Sci Med 1997;45:1121-7.

30 Subramanian SV, Kawachi I. Income inequality and health: what have we learned so far. Epidemiol Rev 2004;26:78-91.

31 Chitnis S. Definition of the terms scheduled castes and scheduled tribes: a crisis of ambivalence. In: Pai Panandiker VA, ed. The politics of backwardness: reservation policy in India. New Delhi: Centre for Policy Research, 1997;104.

32 Filmer D, Pritchett L. Estimating wealth effects without expenditure data - or tears: an application to educational enrollments in states of India. Demography 2001;37:155-74

33 Hallerod B. Poor Swedes, poor Britons: a comparative analysis of relative deprivation. In: Andres A, eds. Empirical poverty research in a comparative perspective. Ashgate: Aldershot, 1998:283-312.

34 Davey Smith G, Gordon D, Kelly M, et al. Inequalities in health in India: the methodological construction of indices and measures, Report submitted to UK Department for International Development., 2003.

35 Subramanian SV, Nandy S, Kelly M, et al. Patterns and distribution of tobacco consumption in India: cross-sectional multilevel evidence from the 1998-99 National Family Health Survey. BMJ 2004;328:801-6.
36 Sundaram K, Tendulkar S. NAS-NSS Estimates of private consumption for poverty estimation: a disaggregated comparison for 1993-94. Economic and Political Weekly, 13 January, 2001:119-29.

37 Deaton A, Dreze J. Poverty and inequality in India: a re-examination. Economic and Political Weekly, 7 September, 2002:3729-48

38 Goldstein H. Multilevel statistical models, 3rd edn. London: Arnold, 2003

39 Subramanian SV. The relevance of multilevel statistical models for identifying causal neighborhood effects. Soc Sci Med 2004;58:1961-7.

40 Subramanian SV, Jones K, Duncan C. Multilevel methods for public health research, In: Kawachi I, Berkman LF, eds. Neighborhoods and health. New York: Oxford University Press, 2003:65-111.

41 Rasbash J, Steele F, Browne W, et al. A user's guide to MLwiN version 2.0. London: Centre for Multilevel Modelling, Institute of Education, 2004.

42 Reddy NR. Body mass index and its association with socioeconomic and behavioural variables among socioeconomically heterogeneous populations of Andhra Pradesh, India. Human Biology 1998;5:901-17.

43 Dhurandhar NV, Kulkarni PR. Prevalence of obesity in Bombay. Int J Obes 1992;16:367-75.

44 Shukla HC, Gupta PC, Mehta HC, et al. Descriptive epidemiology of body mass index of an urban adult population in western India. J Epidemiol Community Health 2002;56:876-80.

45 Sen A. Poverty and famines: an essay on entitlement and deprivation. Oxford: Oxford University Press, 1981.

46 Kundu A. In the name of the urban poor: access to basic amenities 1993. New Delhi: Sage Publications).

47 Lokshin M, Gupta MD, Gragnolati M, et al. Improving child nutrition? The Integrated Child Development Services in India. Development and Change 2005;36:613-40

48 Yajnik CS. Obesity epidemic in India: intrauterine origins? Proc Nutr Soc 2004;63:387-96.

49 Misra A, Vikram NK. Insulin resistance syndrome (metabolic syndrome) and obesity in Asian Indians: evidence and implications. Nutrition 2004;20:482-91.

50 Snehalatha C. Viswanathan V. Ramachandran A. Cutoff values for normal anthropometric variables in Asian Indian adults. Diab Care 2003;26:1380-4.

51 Kusin J, Kardjati S, Renqvist U. Maternal body mass index: the functional significance during reproduction. Eur J Nutr 1994;48:56-67.

52 Gluckman P, Hanson M. The fetal matrix: evolution, development and disease. Cambridge: Cambridge University Press, 2004. 